\title{
Profitability and Financial Leverage: A Study Based on Stitched and Unstitched Textile Sector of Pakistan
}

\author{
Sohaib uz Zaman $^{1 *} \quad$ Ms. Fiza Murghoob ${ }^{2}$ \\ 1. Karachi University Business School, University of Karachi. Main University Road Karachi - 75270. Sindh, \\ Pakistan \\ 2. Department of Business Administration, Federal Urdu University of Arts, Science \& Technology. Main \\ University Road Karachi - 75270. Sindh, Pakistan
}

\begin{abstract}
The major purpose that lies behind conducting this research remains to understand the volatility or consistency of the components of profitability including Return on Assets (ROA), Return on Equity (ROE) and Profit Margin (PM) in the Stitched and Unstitched Industry of Pakistan Textile Sector. The research method used serve the purpose of this study is Independent t-test using SPSS Software. The data considered for conducting this research is taken from the time period from 2012 to 2015, comprising of 44 companies falling in the Pakistan Textile Industry. The key aspect covered by this article remains to analyse the stitched and unstitched industries on the basis of the three profitability ratios and determine which of them are better with respect to their performance in the financial, investing and operating activities that would be identified with the help of ROA, ROE and PM. the results obtained from this study determine that the stitched industry is found with better ROA, ROE and PM as compared to the Unstitched industry.
\end{abstract}

Keywords: Return On Asset (ROA), Return on Equity (ROE), Financial Leverage; Profit Margin, Stitched Textile Sector, Unstitched Textile Sector, profitability.

DOI: $10.7176 /$ RJFA/10-8-11

Publication date: April $30^{\text {th }} 2019$

\section{Introduction}

The textile sector in Pakistan overwhelmingly affects the economy by contributing $57 \%$ to the nation's exports. In the present profoundly aggressive global environment, the textile sector needs to redesign its supply chain management system, improve efficiency, and boost value expansion to sustain. The objective of the textile sector remains to create strategies and programs, which would help in empowering this sector so that it could meet the challenges and accomplish competence worldwide. The Division additionally helps the textile sector in obtaining benchmarks and consistency models, specific trainings and ability advancement, upgrading profitability, and doing research for better innovations to make it dynamic and forward-looking.

Regardless of the industry, the future of any company depend on the flow of the cash, but they the strategies used by them to maintain a profitability are also equally important. This makes all the components of the profitability that are ROA, ROE and PM, an important indicators of the present and future success of the companies. While the myth that the competence of any industry is confined to the confidence and capability of their management is not true, as these determinants are taken as better indicators of the good performance of the company's profitability and level of success.

This further includes that all three types of activities undertaken by the businesses lying in any industry have a great impact on their profitability and growth. Focusing on this point, this article would be including the comparison of the profitability of the business in the Pakistan textile industry with the three most important activities that are financial activities, operating activities, and investing activities.

\subsection{Objectives of the Study}

The objective of this study remains to determine which industry among the Stitched and Unstitched industry of the textile industry of Pakistan has better performance measures as per the business activities held by them.

\section{Literature Review}

This portion of the article would be helping in exploring the literature and determining the functioning of the different activities of the businesses and then analysing them on the basis of the profitability of the businesses associated with them (Tahir et al. 2017). The focus of this study is to determine which industry among the Stitched and Unstitched industry of the textile industry of Pakistan has better performance measures resulted by the business activities held by them. According to (Robinson and Sensoy 2016), the business activities comprise of those activities which are majorly used for the generation of return, that is wealth maximisation. The textile industry in this case is said to be having a greater ratio of production of maximum returns, which could be evidenced from the fact.

This refers to the idea that all the economic activities undertaking taken by the business throughout the course 
of business. The business activities that focus on creating value for the shareholders include, operating activities, investing activities and financing activities (Penman 2015). The cash flows created as well as used by each of these activities could be seen in the annual report of the corporations, specifically within the financial statement or the cash flow statement. The variables of this research could be found in the same financial statement, that are Profit Margin (PM), Return on Assets (ROA) and Return on Equity (ROE) (Tahir et al. 2017).

\subsection{Operating Business Activities}

The Profits margin is said to be most prominent variable to determine the performance of the operating business activities, which has been determined by the Profit Margin, in the income statement (Bouncken and Fredrich 2016). It has been calculated by the below formula:

\section{Profit Margin = Net Profits (or Income)/ Net Sales (or Revenue)}

This clearly shows that the returns and performance of the operating activities of the businesses could easily be evaluated by making use of the ratio between their Income and Revenue (Robinson and Sensoy 2016).

\subsection{Financing Business Activities}

Coming to the next business activity it could be seen that as per (Ali, et al. 2015), the financing activities are based on the cash activities having relation with the owner's equity and noncurrent liabilities. These two comprise of payment of teh dividends, sales of the stock and their repurchasing and most importantly the principal amount of the long term debts. Moreover, (Mahmood, et al. 2017) stated that the decomposition of the ROEs result in the determination of performance of the financial activities of the businesses. The formula used for the calculation of the ROE is:

\section{Return on Equity= Net Income / Shareholders' Equity}

This refers to the idea that the ROE of the financial statement, determine the returns that were resulted through the core financing business activities.

\subsection{Investing Business Activities}

The activities, which are capitalized for more than one year, are known as, investing activities. In the investing business activities the long term assets purchased by the businesses are recorded as a use of cash. Along with this, the capital expenditure is said to be among the most important investing business activities (Bouncken and Fredrich 2016).

Return on Assets (ROA) identifies the earnings generated from the assets or the capital investment of the organisations. In the public limited companies, there is considerable variation observed in the ROA, since the considered industry, that is the textile industry is said to be highly passionate about trading due to great profit associated with it, which makes there ROA varying to their higher extent (Hassan and Marimuthu 2015).

This is the reason it has been preferred by the researchers, such as (Ullah et al. 2016), that when utilizing ROA for comparison analysis, one should either compare it with previous years ROA or similar companies ROA. in this study, companies from same industry are being compared, which would be providing clear evidence regarding the performance of the business through its investing business activities (Javeed and Tabassam 2018).

This can be why once victimization ROA as a comparative live, it's best to check it against a company's previous ROA numbers or against an analogous company's ROA. The ROA figure provides investors a concept of however effective the corporate is in changing the cash it invests into income. The upper the ROA range, the better, as a result of the corporate is earning more cash on less investment (Rajnoha, Novák, and Merková 2016). The formula used for calculating the ROA is given below:

\section{Return on Assets = Net Income/ Total Assets}

\section{Research Methodology}

The data extraction has been made from textile industries of Pakistan, this further includes that 22 companies among the total of 44 companies belong to Stitched Industry, and the rest of the data is taken from Unstitched Industry. The time period chosen for this study remains from 2012 to 2015 . The variables included to this study are Return on Assets (ROA), Return on Equity (ROE) and Profit Margin (PM). The analysis of the given data would be undertaken by making use of the independent t-test, which is also known as student's t-test. This test helps in determining if the chosen groups are having a statistically significant difference between the means. In order to make decision through the results of the provided hypothesis there is a need of setting a significance level, which is also known as alpha $(\alpha)$. The value of the level of significance varies depending on the accuracy of the results required, in this study it would be kept 95\% accuracy, making the value of $\alpha$ to be 0.05 .

\subsection{Hypothesis Testing}

The t-test is based on the hypothesis testing of the given independent samples. There is a need of having separate hypothesis in this study as the test is mean to determine the impact of three different activities, that are, financing 
activity, investing activity, and operating activity of the stitched and unstitched industries.

The general null hypothesis for this independent t-test remains that the two unrelated or independent variables are having equal population means, which could be written as below:

\section{$\mathbf{H}_{0}: \mathbf{u}_{1}=\mathbf{u}_{2}$}

In hypothesis testing, the purpose remains to reject the null hypothesis, and accept the alternative hypothesis. In this alternative hypothesis, the two unrelated or independent variables are not having equal population means, which are expressed below:

\section{$\mathbf{H}_{\mathrm{A}}: \mathbf{u}_{1} \neq \mathbf{u}_{2}$}

The hypotheses that would be used for this study are as follows:

\section{Hypothesis 1:}

- $\mathrm{H}_{0}$ : Null Hypothesis: The means of the Return on Assets (ROA) of the Stitched and Unstitched industry are equal or $\mathbf{u}_{1}=\mathbf{u}_{2}$

- $\mathrm{H}_{\mathrm{A}}$ : Alternative hypothesis: The means of the Return on Assets (ROA) of the Stitched and Unstitched industry are not equal or $\mathbf{u}_{1} \neq \mathbf{u}_{2}$

Hypothesis 2:

- $\mathrm{H}_{0}$ : Null Hypothesis: The means of the Return on Equity (ROE) of the Stitched and Unstitched industry are equal or $\mathbf{u}_{1}=\mathbf{u}_{2}$

- $\mathrm{H}_{\mathrm{A}}$ : Alternative hypothesis: The means of the Return on Equity (ROE) of the Stitched and Unstitched industry are not equal or $\mathbf{u}_{1} \neq \mathbf{u}_{2}$

Hypothesis 3:

- $\mathrm{H}_{0}$ : Null Hypothesis: The means of the Profit Margin (PM) of the Stitched and Unstitched industry are equal or $\mathbf{u}_{1}=\mathbf{u}_{2}$

- $\mathrm{H}_{\mathrm{A}}$ : Alternative hypothesis: The means of the Profit Margin (PM) of the Stitched and Unstitched industry are not equal or $\mathbf{u}_{1} \neq \mathbf{u}_{2}$

\section{Empirical Results Analysis}

The results obtained from the tests applied to the data by making use of the SPSS software are provided below. These results are divided according to the variables on which they are applied starting from the Return on Assets (ROA), then Return on Equity (ROE) and in the end, Profit Margin (PM)i.

\subsection{Independent t-test Analysis for ROA}

The table 1 below obtained through the software includes the groups statistics which determines the mean, standard deviation and standard error of of the sample. The mean of the ROA for the stitched industry is found higher as compared to unstitched industry, which indicates the high returns obtained by the Stitched Industry. Considering the independent $t$ test for testing the significance of the difference in the mean of the two samples, (See table 2), it could be seen that the value of sig. is 0.809 , which is greater than 0.05 (level of significance) hence we will take decision by taking the value of Sig. (2- tailed) where the "equal variances not assumed." Here the Sig (2-tailed) is 0.030 , this value is said to be less than the level of significance chosen for this test, i.e. 0.05 . This could also be expressed as below:

$$
\begin{gathered}
\text { Sig. }(2 \text {-tailed })>\alpha \\
0.03>0.05
\end{gathered}
$$

This refers to the idea that the means of ROA of the Stitched and Unstitched Industry are not equal or in other words statistically significantly different from each other. This refers to the idea that The investing activities undertaken by the stitched industry are better as compared to the unstitched industry.

\section{Table 1: Group Statistics}

\begin{tabular}{|l|l|l|l|l|}
\hline \multicolumn{2}{|l|}{ Industry } & Mean & Std. Deviation & Std. Error Mean \\
\hline \multirow{2}{*}{ ROA } & Stitched Industry & .110 & .005 & .011 \\
\cline { 2 - 5 } & Unstitched Industry & .044 & .098 & .010 \\
\hline
\end{tabular}




\begin{tabular}{|l|l|l|l|l|}
\hline \multicolumn{2}{|c|}{ Table 2: Independent Samples Test } \\
\hline \multirow{2}{|c|}{} & \multicolumn{2}{|l|}{ t-test for Equality of Means } & \multicolumn{2}{l|}{ Sig. (2-tailed) } \\
\cline { 3 - 5 } & & Sig. & Df & 0.030 \\
\hline \multirow{2}{*}{ ROA } & Equal variances assumed & 0.809 & 174.00 & 0.030 \\
\cline { 2 - 5 } & Equal variances not assumed & & 173.18 & \\
\hline
\end{tabular}

\subsection{Independent t-test Analysis for ROE}

Considering the independent $t$ test for ROE, it could be seen that the significance value is 0.00 , which is less than 0.05 , hence we will be taking decision by considering the sig. (2-tailed) value where "equal variances assumed", (See table 4). Here the Sig. (2-tailed) is 0.48 , when the variances have been assumed equal, against the value of level of significance, 0.05 . Here again the significance value is greater than the value of labe expressed as below:

$$
\begin{gathered}
\text { Sig. }(2 \text {-tailed })>\alpha \\
0.048>0.05
\end{gathered}
$$

Hence, we reject the null hypothesis, and this could be concluded that the means of the Return on Equity (ROE) of the Stitched and Unstitched industry are not equal. This could further be stated that the stitched industry which is found with better mean than the unstitched industry, which makes the equity return from the stitched industry to be better than those obtained from the unstitched industry. As discussed in the literature review, the ROE represents the financing activities held by the companies, in this case, the high mean of the ROE of the stitched industry also represents that the financial activities at the stitched industry are better dealt as compared to the unstitched industry.

\section{Table 3: Group Statistics}

\begin{tabular}{|c|c|c|c|c|}
\hline \multicolumn{5}{|c|}{ Table 4: Independent Samples Test } \\
\hline & & \multicolumn{3}{|c|}{ t-test for Equality of Means } \\
\hline & & Sig. & Df & Sig. (2-tailed) \\
\hline \multirow[t]{2}{*}{ ROE } & Equal variances assumed & 0.00 & 174 & .048 \\
\hline & Equal variances not assumed & & 95.975 & .049 \\
\hline
\end{tabular}

\begin{tabular}{|l|l|l|l|l|}
\hline \multicolumn{2}{|l|}{ Industry } & Mean & Std. Deviation & Std. Error Mean \\
\hline \multirow{2}{*}{ ROE } & Stitched Industry & -.3439 & 1.79780 & .19165 \\
\cline { 2 - 5 } & Unstitched Industry & .0474 & .40886 & .04358 \\
\hline
\end{tabular}

The profit margin of the businesses are said to be associated with their operating activities. This makes it clear that the industry which has higher profit margin is said to be more successful. The two industries in this context, that are stitched and unstitched industry are both said to be highly probability, as could be seen from the great share of the textile industry in the growth of the economy of Pakistan.

The independent $t$ test for the profit margin of the stitched and unstitched industry in this context determine that the significance value is 0.239 , which is greater than 0.05 , hence we will be taking decision by considering the sig. (2-tailed) value where "equal variances assumed", (See table 6). In this table, the sig. (2-tailed) value in the table 6 is 0.047 , against the level of significance of 0.05 , which refers to the idea that:

$$
\begin{gathered}
\text { Sig. }(2 \text {-tailed })>\alpha \\
0.047>0.05
\end{gathered}
$$

Hence, we reject the null hypothesis, and concluded that the means of the PM of the Stitched and Unstitched 
industry are not equal and are statistically significantly different from each other. In order to determine which one among these industries are producing better PM, the mean of the data could be taken into consideration. Looking at the table 5, it could be seen that the mean of the PM of the Stitched industry is 0.5345 , which is greater than the mean of the Unstitched Industry that is 0.1749 . Hence, the PM of the stitched industry is better than that of the unstitched industry.

\begin{tabular}{|c|c|c|c|c|}
\hline \multicolumn{5}{|c|}{ Table 5: Group Statistics } \\
\hline \multicolumn{2}{|c|}{ Industry } & Mean & Std. Deviation & Std. Error Mean \\
\hline \multirow[t]{2}{*}{$\mathrm{PM}$} & Stitched Industry & .5345 & 2.54139 & .27091 \\
\hline & Unstitched Industry & .1749 & 2.14710 & .22888 \\
\hline
\end{tabular}

\begin{tabular}{|c|c|c|c|c|}
\hline & & \multicolumn{3}{|c|}{ t-test for Equality of Means } \\
\hline & & Sig. & Df & Sig. (2-tailed) \\
\hline \multirow[t]{2}{*}{ PM } & Equal variances assumed & 0.239 & 174 & .047 \\
\hline & Equal variances not assumed & & 169.278 & .047 \\
\hline
\end{tabular}

\section{Conclusion}

This study focuses on understanding financial performance of business activities. In order to understand this aspect, this study compares the two major sectors of the Pakistan textile industry that are the Stitched and Unstitched Industry. The three important business activities, namely, investing, financial, operating activities are then determined in these industries by making use of variables, ROA, ROE, and PM, respectively.

The results obtained from the chosen analysis, that was independent $t$ test, shows that for all three business activities, are better off in the stitched industry. The conclusion is first made on the basis of the hypothesis testing, where it has been found that the mean of the two industries for each of the variables is different. Lastly, the mean of the groups show that the mean for the ROA, ROE and PM of the stitched industry is higher than the mean of the unstitched industry.

\section{Reference}

Ali, A., X. Fengju, A.G. de Andrade, and U. Saeed. "Determinants of Dividend Policy: Evidence from Textile Industry of Pakistan." International Journal of Arts \& Sciences 8, no. 8, 2015: 45.

Bouncken, Ricarda B., and Viktor Fredrich. 2016. "Business Model Innovation in Alliances: Successful Configurations.” Journal of Business Research. https://doi.org/10.1016/j.jbusres.2016.01.004.

Fernandes, T.I.M. Financial Literacy Levels of Small Businesses Owners and it Correlation with Firms' Operating Performance. 2016.

Hassan, Rohail, and Maran Marimuthu. 2015. "Corporate Governance Effect on Ownership and Control in Firms: An Empirical Evidence from Pakistan." International Journal of Business and Management. https://doi.org/10.5539/ijbm.v10n8p212.

Javeed, Laila, and Rehana Tabassam. 2018. "Financial Leverage and Financial Performance: Empirical Evidence From Listed Textile Industry of Pakistan." International Journal of Accounting and Financial Reporting. https://doi.org/10.5296/ijafr.v8i4.14136.

Khan, F., and A. Chishti. Analyzing Determinants of Dividend Payout Practices in Pakistan Textile Industry (20082013). 2017.

Mahmood, B., M.S. Iqbal, M.J. Zafar, and B. Khalid. "Textile Industry Socializing, Economic Gains and Capital Structure: A Case Study of Faisalabad." Pakistan. J. Appl. Environ. Biol. Sci 7, no. 9, 2017: 1-7.

Penman, S.H. Financial Ratios and Equity Valuation. Wiley Encyclopedia of Management, 2015.

Penman, Stephen H. 2015. "Financial Ratios and Equity Valuation." Wiley Encyclopedia of Management. https://doi.org/10.1002/9781118785317.weom010079.

Rajnoha, Rastislav, Petr Novák, and Martina Merková. 2016. "Relationships Between Investment Effectiveness Controlling and Business Performance.” Montenegrin Journal of Economics. https://doi.org/10.14254/1800- 
5845/2016.12-2.1.

Robinson, David T., and Berk A. Sensoy. 2016. "Cyclicality, Performance Measurement, and Cash Flow Liquidity in Private Equity." Journal of Financial Economics. https://doi.org/10.1016/j.jfineco.2016.09.008.

Tahir, Safdar Husain, Sara Sohail, Saba Babar, and Irtaza Oayyum. 2017. "Effect of Corporate Governance Index on Dividend Policy: An Investigation of Textile Industry of Pakistan." Oeconomica Jadertina. https://doi.org/10.15291/oec.300.

Tauseef, S., H.D. Lohano, and S.A. Khan. "Effect of debt financing on corporate financial performance: evidence from textile firms in Pakistan." Pakistan Business Review, 2015: 903.

Ullah, Hidayat, Shahab e. Saqib, and Hazrat Usman. 2016. "The Impact of Dividend Policy on Stock Price Volatility: A Case Study of Selected Firms from Textile Industry in Pakistan.” International Journal of Academic Research in Economics and Management Sciences. https://doi.org/10.6007/ijarems/v4-i4/2033. 